\title{
SCIDiC
}

\author{
International Journal of Dentistry and Oral Science (IJDOS) \\ ISSN: 2377-8075
}

\section{Knowledge Attitude and Practice Towards Denture Hygiene Among Interns, Specialists and Practitioners}

Research Article

Gayathri R Menon ${ }^{1}$, Kiran Kumar Pandurangan ${ }^{2 *}$

${ }^{1}$ Saveetha Dental College and Hospitals, Saveetha Institute of Medical and Technical Sciences, Saveetha University, Chennai, India.

${ }^{2}$ Senior Lecturer, Department of Prosthodontics, Saveetha Dental College and Hospitals, Saveetha Institute of Medical and Technical Sciences,

Saveetha University, Chennai, 600077, India.

\section{Abstract}

\begin{abstract}
A successful complete denture treatment can be achieved when the patients are motivated and aware of appropriate denture wear and oral hygiene maintenance. General and oral health could improve through quality of life. Hence, the purpose of this study was to evaluate denture hygiene knowledge attitude and practice towards patients education among dental interns and practitioners. A total of 190 participants were included in the study. A cross-sectional survey was conducted among interns and practitioners. The questionnaire was divided into 3 parts based on knowledge, attitude and practice and the collected data were analysed using SPSS software. Chi square test was performed to determine the statistical significance. In this present study, majority of participants $(93.7 \%)$ were aware of plaque accumulation in dentures and about $50.5 \%$ of the participants agreed that explaining denture hygiene instructions to patients was time consuming. $45.3 \%$ of the participants recommended denture cleansing tooth brush and $42.6 \%$ of the participants recommended regular toothbrush for denture cleansing. Association between level of education and knowledge of the respondents about removal of denture adhesive on a daily basis showed positive association $(\mathrm{p}<0.05)$. Association between level of education and the medium by which instructions were given to patients shows positive significance ( $\mathrm{p}$ value $<0.05)$. Positive association was present between place of practice and explaining denture hygiene instructions to patients is very time consuming ( $\mathrm{p}$ value $<0.05$ ). Association between gender and recall program for complete denture patients is not important as denture teeth are artificial teeth, showed significance $(\mathrm{p}$ value $<0.05)$. Association between gender and methods which respondents recommend for denture cleansing to patients was statistically not significant ( $\mathrm{p}$ value $>0.05$ ). Knowledge, attitude and practice among interns and practitioners had limited knowledge on denture cleansers and the importance of denture hygiene practice.
\end{abstract}

Keywords: Complete Denture; Denture Cleaners; Denture Hygiene; Missing Teeth; Survey.

\section{Introduction}

Recent decades, there has been an increase in the number of elderly patients and the need of dentures to replace missing teeth has also increased [1-3]. Providing conventional dentures (complete dentures) is a usual process to restore the anatomical structures, form, chewing function and esthetics [4]. Effectual maintenance of oral hygiene plays a vital role to improve the quality of life and success of prosthodontic treatment [5].

The aggregation of stains, soft and hard debris on removable dentures may be an unpleasant consequence on the patient's oral health status and many denture wearers find it very difficult to clean the denture [6]. Few studies indicate that many patients fail to keep their dentures clean and continue to use the dirty dentures $[7,8]$. Inappropriate cleaned dentures which may result in halitosis, poor esthetics and gum irritation like denture-induced stomatitis [9]. In addition, habits such as wearing of complete dentures at night have proved to cause denture related stomatitis [10-14]. Denture stomatitis is one of the most common fungal infections that are seen in patients who wear removable dentures [15]. Several studies conducted on denture stomatitis, nearly $15 \%$ to $70 \%$ of denture wearers affected different populations worldwide [16-18].

The micro-porous surfaces on acrylic removable dentures provide

*Corresponding Author:
Kiran Kumar Pandurangan,

Senior Lecturer, Department of Prosthodontics, Saveetha Dental College and Hospitals, Saveetha Institute of Medical and Technical Sciences, Saveetha University, Chennai, 600077, India.

Tel: $+91-7010782807$

E-mail: kirankumar.sdc@saveetha.com

Received: October 07,2020

Accepted: November 22, 2020

Published: November 27, 2020

Citation: Gayathri R Menon, Kiran Kumar Pandurangan. Knowledge Attitude and Practice Towards Denture Hygiene Among Interns, Specialists and Practitioners. Int J Dentistry Oral Sci. 2020;7(11):1111-1120. doi: http://dx.doi.org/10.19070/2377-8075-20000221

Copyright: Kiran Kumar Pandurangan ${ }^{\circ} 2020$. This is an open-access article distributed under the terms of the Creative Commons Attribution License, which permits unrestricted use, distribution and reproduction in any medium, provided the original author and source are credited. 
a wide span of different environments in order to carry microorganisms which may harm the health of a denture patient. [8, 19, 20]. There are generally two approaches recommended to the patient's Dentures that can be cleansed mechanically, chemically or through a combination of these [21-23]. Denture care is handled easily, effective for removal of organic/inorganic deposits and stains. Thus, the brushing is the most common way to clean the removable dentures. However, the use of toothbrushes is effective and has better outcomes [20]. To have effective and regular denture hygiene, it is important for dentists to provide proper denture hygiene instructions to the patients [24]. Although, Complete denture wearers pay less attention towards the oral hygiene in comparison to the dentate [23]. Dentists should encourage, motivate and guide the patients through providing them and ways to control plaque which maintain good oral hygiene $[25,26]$.

Studies have shown that most denture wearers have poor oral hygiene, poor denture cleanliness which may facilitate the accumulation of attribute biofilm [7, 8, 17, 27]. Most of the researchers have concentrated on the denture wearers knowledge and attitude towards denture cleansing $[5,28,29]$. The study focused more on the knowledge, attitude and practice of the dentists towards patient education at the time of denture delivery and there are very few studies only available. Previously our team has conducted numerous original studies [30-44] over the past 5 years. The plan for this study stemmed from the contemporary interest in our community.

\section{Materials and Methods}

The survey was conducted among dental interns and practitioners using a self administered questionnaire. We modified and reviewed a questionnaire conducted previously published by Suresh $\mathrm{V}$ et al., [26]. A total of 190 participants have been randomly enrolled. An online questionnaire which was distributed electronically using a link generated by google forms. Demogrpahic information was obtained from the participants such as gender, level of education,year of practice,place of work. The questionnaire consisted of 17 questions closed ended questions which were divided into 3 parts based on knowledge,attitude and practice. The first part contains 5 questions related to knowledge associated with denture hygiene maintenance. Second part contains 5 questions related to the attitude towards denture hygiene instructions during delivery of the dentures to the patients there were not many literatures available. Third part contains 7 questions related to the denture hygiene practice recommended. Informed consent was obtained from all participants. The participants' information was kept anonymous and also confidential. The collected data were tabulated and imported into the IBM SPSS Statistics for Windows, Version 20.0. Chicago: SPSS Inc program to extract the means and percentages. Chi-square test was performed for nonparametric study and was enrolled to determine the statistical difference between the two variables where $\mathrm{p}$ value $<0.05$ is considered statistically significant with a confidence interval of $95 \%$. Pie charts and bar charts were used for pictorial representation of the result of the present study.

\section{Results and Discussion}

In the present study, the demographic data of the respondents have been shown in table 1 . Among 190 participants $61.6 \%$ were females and $38.4 \%$ were males. The majority of participants were females $61.6 \%$. (Figure 1). The level of education of the participants were more in interns by $67.9 \%$ followed by $16.3 \%$ were general practitioners and $15.8 \%$ were specialties (Figure 2). The year of practice of the participants were $83.2 \%$ for $1-3$ years, $14.7 \%$ for $4-10$ years and $2.1 \%$ for $11-15$ years (Figure 3 ). The place of work was Dental College for $73.7 \%$ and private clinic for $26.3 \%$ (Figure 4). According to the study, about $93.7 \%$ of participants were aware that dentures accumulate oral plaque, $4.7 \%$ of participants were aware that these oral plaques that get accumulated in the dentures and the rest $31.6 \%$ (Figure 5).

Nearly $78.4 \%$ of participants reported that oral plaque on complete dentures are associated with denture stomatitis and other systemic diseases, $15.3 \%$ of participants reported that it will not be associated with denture stomatitis and other systemic diseases and the remaining $6.3 \%$ (Figure 6 ). About $47.9 \%$ of the participants recommended that regular tooth pastes are advisable for denture cleansing, $37.4 \%$ of the participants disagreed with that regular toothpaste advisable for denture cleansing and $14.7 \%$ are not aware whether regular toothpastes are advisable for denture cleansing. (Figure 7). About $44.2 \%$ reported that cleaning the tissue bearing side of the denture affect its retention in the mouth, $35.3 \%$ of participants disagreed with that denture cleansing on the tissue bearing side cause loss of retention and the remaining

Table 1. Showing demographic data of participants, shows distribution of respondents based on gender, level of education (Interns, Specialists, General practitioners), years of practice (1-3 years,4-10 year,11-15 years), place of work (dental college, private clinic).

\begin{tabular}{|c|c|c|c|}
\hline $\begin{array}{c}\text { Demographic } \\
\text { Variables }\end{array}$ & Categories & $\begin{array}{c}\text { No. Of } \\
\text { Respondents }\end{array}$ & Percentage \% \\
\hline \multirow{2}{*}{ Gender } & Male & 73 & $38.40 \%$ \\
& Female & 117 & $61.60 \%$ \\
\hline \multirow{2}{*}{ Level Of Educa- } & Interns & 129 & $67.90 \%$ \\
tion & Specialists & 30 & $15.80 \%$ \\
& General Practitioners & 31 & $16.30 \%$ \\
\hline \multirow{3}{*}{ Years Of Practice } & $1-3$ year & 158 & $83.20 \%$ \\
& 4-10 year & 28 & $14.70 \%$ \\
& $11-15$ years & 4 & $2.10 \%$ \\
\hline \multirow{2}{*}{ Place Of Work } & Dental College & 140 & $73.70 \%$ \\
& Private Clinic & 50 & $26.30 \%$ \\
\hline
\end{tabular}


Figure 1. Pie chart representing the gender of the study population. $38.4 \%$ of the participants were male and $61.6 \%$ of the participants were female.

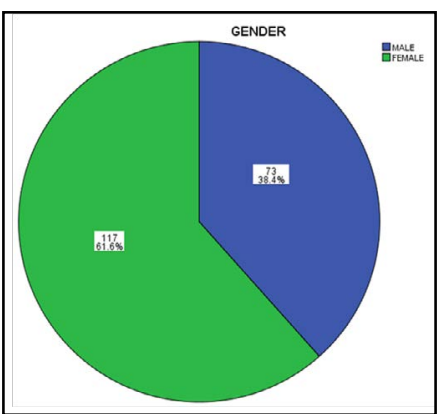

Figure 2. Pie chart represents the level of education of the study population. $67.9 \%$ of the participants were interns , $15.8 \%$ were specialists and $16.3 \%$ were general practitioners.

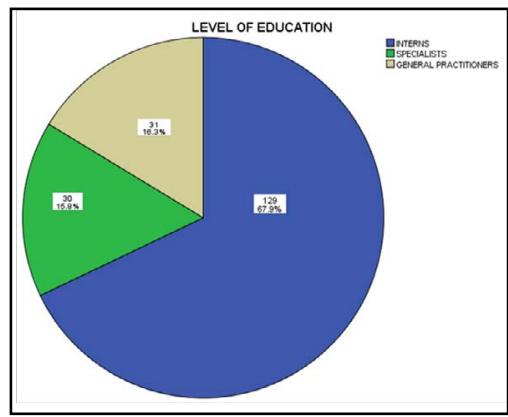

Figure 3. Pie chart represents the year of practice of the study population. Respondents of 1-3 years of experience 83.2\%, 4-10 years of experience $14.7 \%$ and $11-15$ years of experience $2.1 \%$.

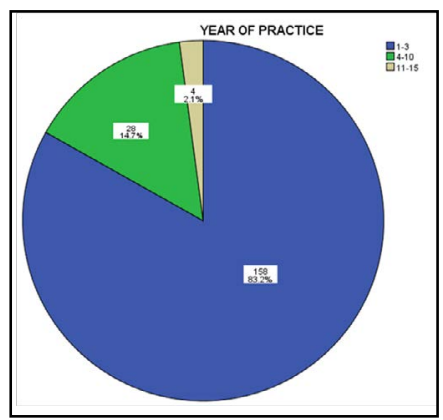

Figure 4. Pie chart represents the place of work of the study population. $73.7 \%$ of the respondents work at dental college and $26.3 \%$ of the respondents work at private clinics.

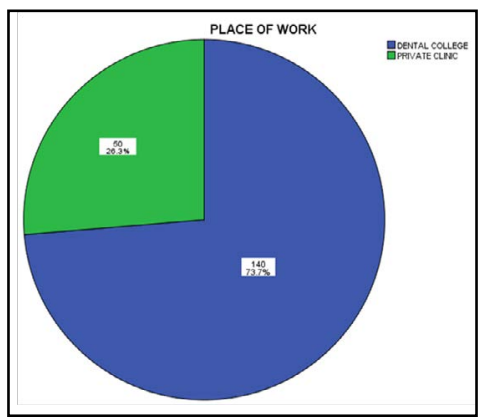

Figure 5. Pie chart representing the responses to the question: Dentures accumulate oral plaque. 93.7\% are aware that dentures accumulate oral plaque $4.7 \%$ are not aware that dentures accumulate oral plaque $1.6 \%$ don't know whether dentures accumulate oral plaque.

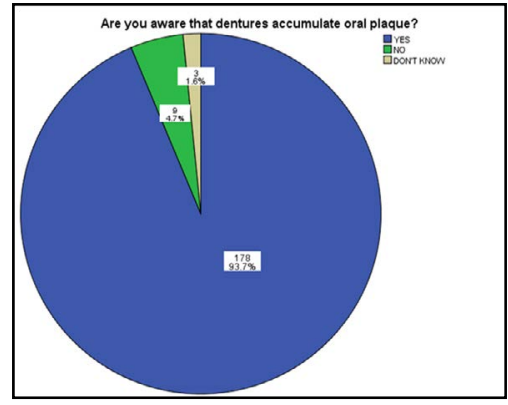


Figure 6. Pie chart representing the responses to the question: Oral plaques on complete denture associated denture stomatitis and other systemic diseases. $78.4 \%$ participants agreed that oral plaque on complete dentures cause denture stomatitis, $15.3 \%$ disagreed that oral plaque on complete dentures cause denture stomatitis and $6.3 \%$ participants don't know that oral plaque on complete dentures cause denture stomatitis.

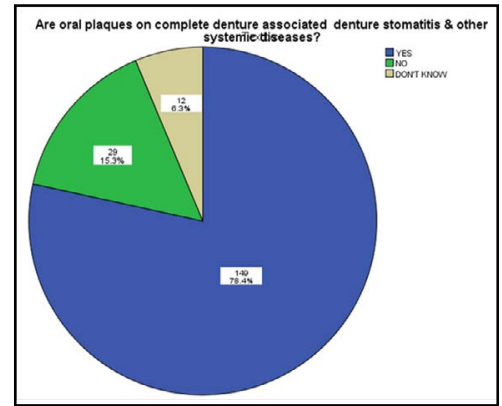

Figure 7. Pie chart representing the responses to the question: Regular toothpaste advisable for denture cleansing. $47.9 \%$ of participants agreed that regular toothpaste is advisable for denture cleansing, $37.4 \%$ of participants disagreed that regular toothpaste is advisable for denture cleansing and $14.7 \%$ of participants don't know that regular toothpaste is advisable for denture cleansing.

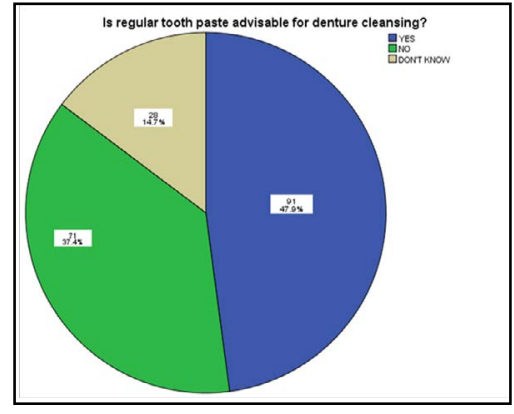

$20.5 \%$ participants didn't know that denture cleansing on the tissue bearing side causes loss of retention (Figure 8).

Nearly $63.7 \%$ respondents said that placement of denture in sodium hypochlorite for a longer time causes damage, $15.3 \%$ strongly disagreed and 21.1\% participants didn't know (Figure 9). In this survey, most of the participants $50.5 \%$ agreed that explaining denture hygiene instructions to the patients can be time consuming, $43.2 \%$ of participants disagreed and $6.3 \%$ of the participants didn't know (Figure 10). About 51.1\% disagreed that it is not necessary to provide denture hygiene instructions to elderly patients because they tend to not follow it , 35.3\% agreed and the rest $13.7 \%$ didn't know (Figure 11). Majority of the $51.6 \%$ participants believed that the recall program for complete denture patients is not important, 33.2\% agreed and 15.3\% didn't know (Figure 12). Nearly $51.1 \%$ of participants reported that it is not important to educate the patients on the impact of denture hygiene on systemic health and $39.3 \%$ disagreed and the remaining $12.6 \%$ didn't know about it (Figure 13). About 39.5\% agreed that denture adhesive need not be removed completely and reapplied on a daily basis, while $38.9 \%$ of participants disagreed and $21.6 \%$ of the participants did not know (Figure 14).

In this study, about $87.9 \%$ of participants reported that they instruct patients regarding the rising of dentures using the denture cleansing method and the rest $12.1 \%$ of participants strongly disagreed (Figure 15). Majority of the participants $42.1 \%$ use verbal and practical demo to explain the denture hygiene instructions and least it will be instructed by written 4.2\% [45] (Figure 16). About $45.3 \%$ of the participants recommended denture cleansing toothbrush, followed by use of regular toothbrush $42.6 \%$ and don't recommend any toothbrush $12.1 \%$ (Figure 17). Nearly 50\% reported that they will recommend cleansing of the denture twice daily followed by once daily $33.7 \%$, once in a week $5.8 \%$ and once in 3-4 days 5.8\%, More than 3 times a day $4.2 \%$ and Never $0.5 \%$ (Figure 18).

Majority of the participants $92.1 \%$ recommend the patients to remove the denture at night and the remaining $7.9 \%$ do not recommend (Figure 19). About $83.7 \%$ reported that they will recall patients for review and the rest $16.3 \%$ don't recall patients for review (Figure 20). About $35.8 \%$ of participants recommend cleansing the denture with water followed by alkaline per-oxide tablet $23.7 \%$, bruising with soap water $21.6 \%$ and diluted hypochlorite $18.6 \%$ (Figure 21 ). In the current study, Interns are more likely to concur than specialists and practitioners that denture need not be removed completely and reapplied on a daily basis $(\mathrm{p}<$ 0.05) (Figure 22). Interns are more probable to instruct the verbal and practical demo than specialists and practitioners $(p<0.05)$ (Figure 23). Hence, this association was found to be statistically significant. There is significant association between the place of practice and denture hygiene instructions to denture wearers ( $p$ $<0.05$ ) (Figure 24). Furthermore, females were more probable to concur than males that a recall program for complete denture patients has no importance due to denture teeth $(\mathrm{p}<0.05)$. Therefore, which shows statistically significant (Figure 25). Based on the results, females were more likely to recommend cleaning the denture by brushing with water $(\mathrm{p}>0.05)$ (Figure 26).

Denture hygiene is a familiar problem in elderly patients worldwide and confronted by the prosthotic dentists [45]. Especially the elderly patients, who are not able to maintain good denture hygiene by reason of mental and physical handicap [26, 46]. The knowledge among the dentist on denture hygiene maintenance is very important. Dentists should have adequate knowledge to train and instruct the patients on the significance of denture hygiene. Recall the patient on a regular interval to ensure if denture hygiene is maintained [25]. 
Figure 8. Pie chart representing the responses to the question: Cleansing the tissue bearing side affects its retention. $44.2 \%$ of the participants agreed that denture cleansing on the tissue bearing side causes loss of retention,35.3\% of participants disagreed that denture cleansing on the tissue bearing side causes loss of retention and $20.5 \%$ of participants does not know that denture cleansing on the tissue bearing side causes loss of retention.

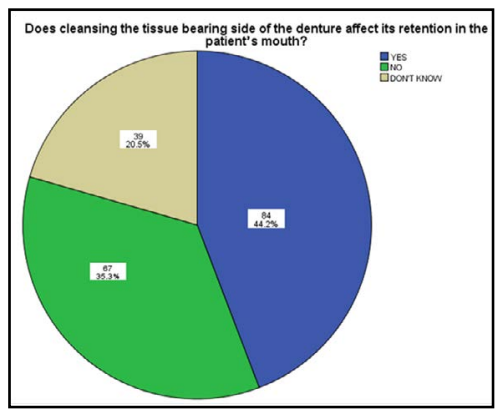

Figure 9. Pie chart representing the responses to the question: Placement of denture in sodium hypochlorite for longer period causes damage. $63.7 \%$ of respondents agreed that placement of denture in sodium hypochlorite for a longer time causes damage, $15.3 \%$ of respondents disagreed that placement of denture in sodium hypochlorite for a longer time causes damage and $21.1 \%$ of respondents does not know that placement of denture in sodium hypochlorite for a longer time causes damage.

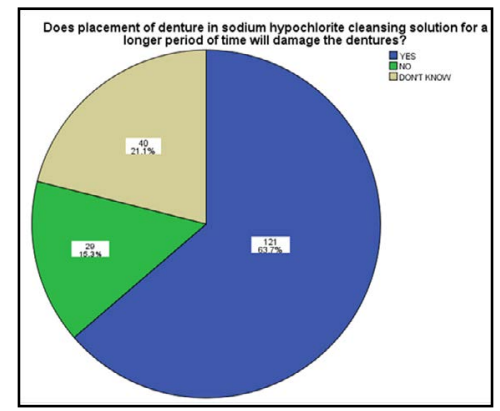

Figure 10. Pie chart representing the responses to the question: Explaining dental hygiene instructions to patients is time consuming. $50.5 \%$ of respondents agreed that explaining dental hygiene instructions to patients was time consuming, $43.2 \%$ of respondents disagreed that explaining dental hygiene instructions to patients was time consuming and $6.3 \%$ of respondents did not know that explaining dental hygiene instructions to patients was time consuming.

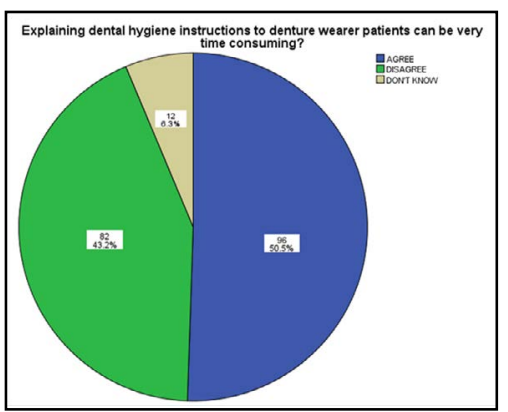

Figure 11. Pie chart representing the responses to the question: Providing denture hygiene instructions to patients is of no use. $35.3 \%$ of respondents agreed that providing denture hygiene instructions to patients is of no use because they do not follow it, $51.1 \%$ of respondents disagreed that providing denture hygiene instructions to patients is of no use because they do not follow it and $13.7 \%$ of respondents does not know that providing denture hygiene instructions to patients is of no use because they do not follow it.

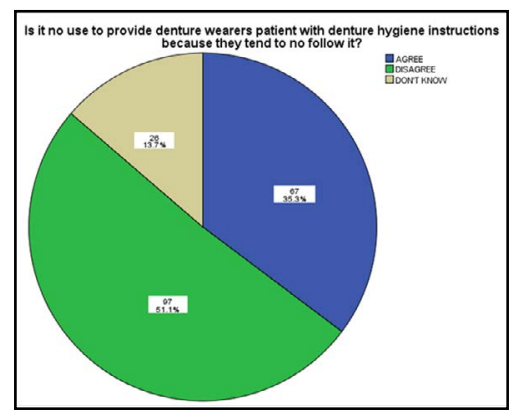

However, these findings were disparity with previous study was done by Razan Fahad AlEidan et al., [25] In the current study, most of the participants reported that educating patients regarding the impact of denture hygiene on systemic health is not important and $39.5 \%$ of participants believe that denture adhesives need not be cleaned completely and reapplied daily on a daily basis. It was found from the study that most of the practitioners recommended cleansing of dentures twice daily. These findings were not in agreement with Razan Fahad AlEidan et al.,[25] In the present study, nearly $87.9 \%$ of participants recommended that they advise the patients on denture cleansing methods. In a previous 
Figure 12. Pie chart representing the responses to the question: Recall program for complete denture patients is not important. $33.2 \%$ of respondents agreed that recall program for complete denture patients is not important, $51.6 \%$ of respondents disagreed that recall program for complete denture patients is not important and $15.3 \%$ of respondents does not know that recall program for complete denture patients is not important.

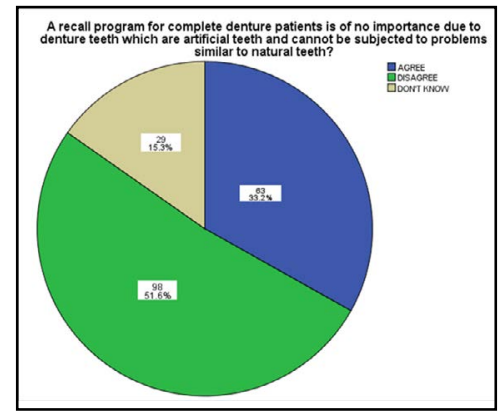

Figure 13. Pie chart representing the responses to the question: Educating patients regarding the impact of denture hygiene on systemic health is not important. $36.3 \%$ of respondents who agreed that educating patients regarding the impact of denture hygiene on systemic health is not important, $51.1 \%$ of respondents disagreed that educating patients regarding the impact of denture hygiene on systemic health is not important and $12.6 \%$ of respondents don't know that educating patients regarding the impact of denture hygiene on systemic health is not important.

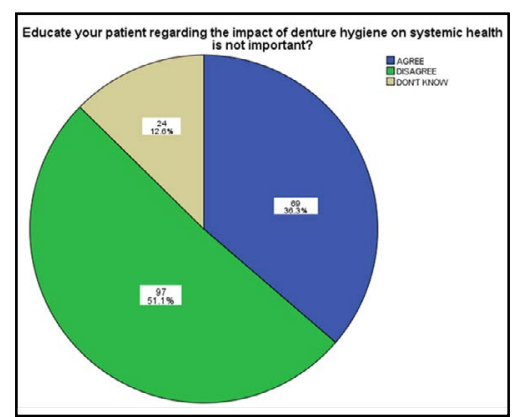

Figure 14. Pie chart representing the responses to the question: Denture adhesives need not be cleaned completely and reapplied daily. $39.5 \%$ of respondents agreed that denture adhesives need not be cleaned completely and reapplied daily, $38.9 \%$ of respondents disagreed that denture adhesives need not be cleaned completely and reapplied daily and $21.6 \%$ of respondents does not know that denture adhesives need not be cleaned completely and reapplied daily.

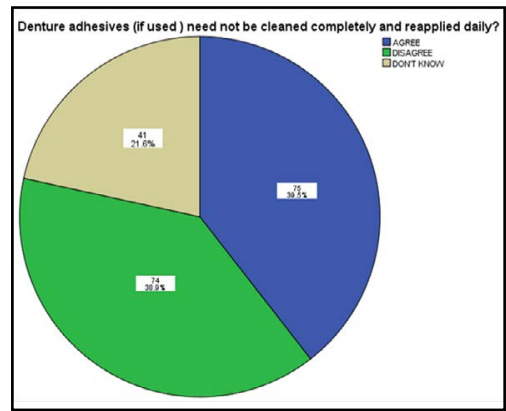

Figure 15. Pie chart representing the responses to the question: Advise patients on rinsing the dentures using denture cleansing methods. $87.9 \%$ of respondents agreed that they advise patients on rinsing the dentures using denture cleansing methods and $12.1 \%$ of respondents disagreed that they advise patients on rinsing the dentures using denture cleansing methods.

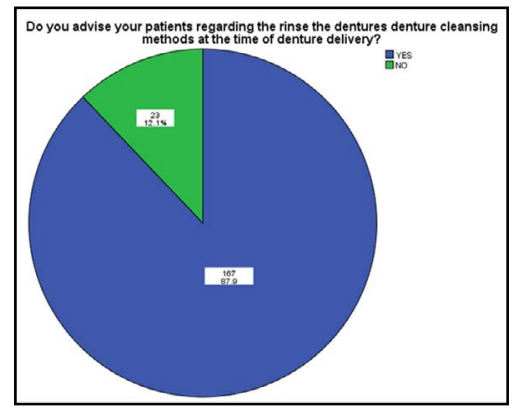

study, which was conducted with a variance study done by Amand Peracini et al., and reported that $51.89 \%$ of patients did not get proper advice on denture cleansing [47]. Similar study was seen in previous literature, proper instructions on denture cleansing was obtained only for 40 patients out of 234 patients [8]. We observed that the most common method to use for cleansing the dentures using brush with water by $35.8 \%$. Majority of the participants reported verbal and practical demos (42.1\%) for providing denture instructions to the patients. This study is contradictory with previous study conducted by Vinay Suresan et al., [26] In the present study, most of the practitioners recommend the use of denture cleansing brush (45.3\%) followed by regular toothbrush $(42.6 \%)$ 
Figure 16. Pie chart representing the responses to the question: medium of instructions. $33.2 \%$ of respondents instructs by verbal, $4.2 \%$ of respondents instructs by written, $4.7 \%$ respondents instructs by practical demo, $7.4 \%$ of respondents instructs by verbal and written, $42.1 \%$ of respondents instructs by verbal and practical demo and $8.4 \%$ of respondents who instructs by written and practical demo.

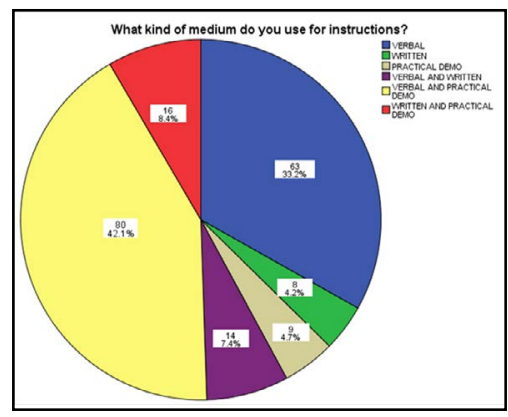

Figure 17. Pie chart representing the responses to the question: brush that is recommended for denture cleansing by you. $12.1 \%$ of respondents don't recommend any toothbrush, $42.6 \%$ of respondents recommend regular toothbrush and $45.3 \%$ of respondents recommend denture cleansing brush.

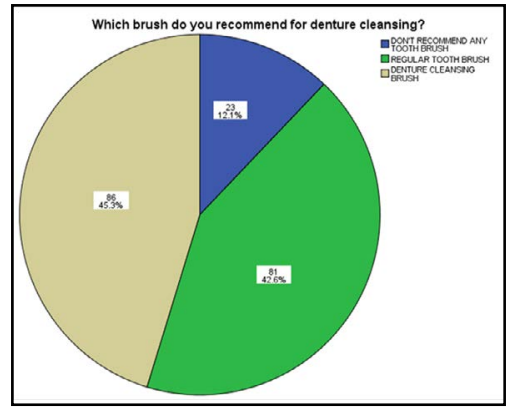

Figure 18. Pie chart representing the responses to the question: frequency of cleansing the denture recommended. $33.7 \%$ of respondents recommend cleansing of denture once daily, $50 \%$ of respondents recommend twice daily, $5.8 \%$ of respondents recommend once in a week ,5.8\% of respondents recommend once in 3-4 days, $4.2 \%$ of respondents recommend more than 3 times a day and $0.5 \%$ of respondents never recommend.

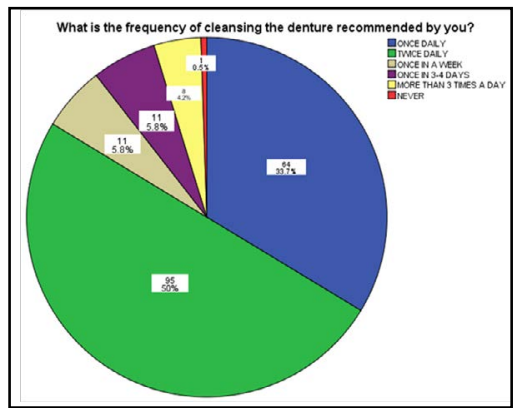

Figure 19. Pie chart representing the responses to the question: instruct patients to remove their dentures at night . $92.1 \%$ of respondents recommend removing the dentures at night and $7.9 \%$ of respondents do not recommend removing the dentures at night.

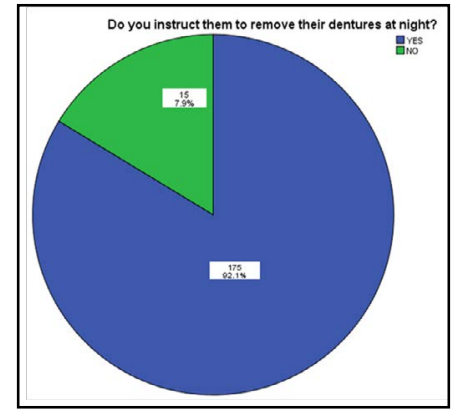

for cleansing the dentures. Majority of the participants recommend removing the dentures at night. A periodic denture check up recommended by most of the interns and practitioners. These results were concurrent with Razan Fahad AlEidan et al.,[25].

The limitations of this study, it is limited to a smaller number of participants. In future, especially for the speciality, age among dentists should be carried out in a large population.

\section{Conclusion}

Based on the results of this study, it can be concluded that interns, specialists and practitioners had limited knowledge in denture hygiene, denture cleansing methods and materials. It is essential to spread awareness among dentists to educate their patients about correct methods and practices to clean and maintain their dentures. Educators pay more attention to reinforce the skill of their graduates in order to improve dental care services. Dental profes- 
Figure 20. Pie chart representing the responses to the question:Do you recall patients for periodic check-up. 83.7\% of respondents recall the patients for check up and $16.3 \%$ of respondents do not recall patients for check up.

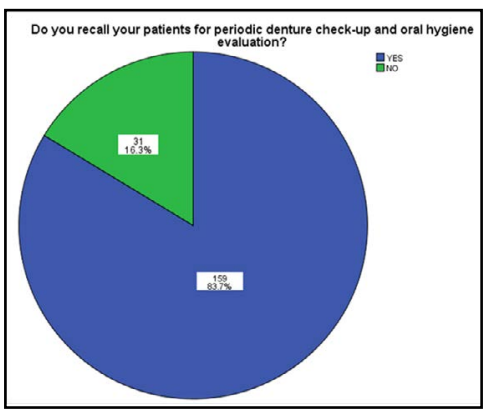

Figure 21. Pie chart representing the responses to the question: denture cleansing method recommended.35.8\% of respondents recommend cleansing the denture by brushing with water, $21.6 \%$ of respondents recommend cleansing the denture by brushing with soap water, $18.6 \%$ of respondents recommend cleansing the denture by immersing them in dilute alkaline hypochlorite and $23.7 \%$ of respondents recommend cleansing the denture by immersing them in peroxide tablet / powder.

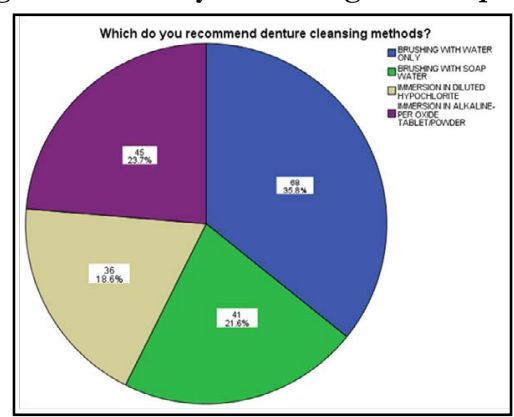

Figure 22. Bar chart depicting the association between level of education and knowledge of the dental interns and practitioners about removal of denture adhesive and reapplying it on a daily basis. $\mathrm{X}$ axis denotes level of education and $\mathrm{Y}$ axis denotes number of respondents. In this graph, most of the interns chose the response "aware"(Blue) colour. Chi square test shows statistical difference among interns, specialists and practitioners [Pearson Chi square $\mathrm{p}$ value $=0.001(\mathrm{p}>0.05)]$.

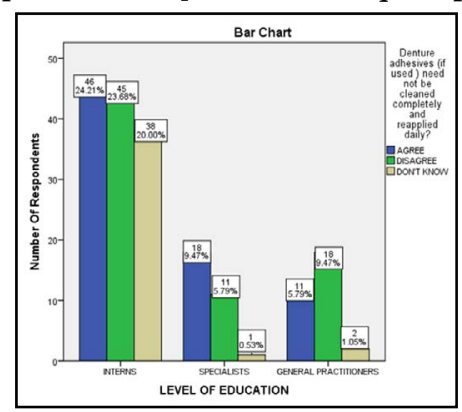

Figure 23. Bar chart depicting the association between level of education and the medium by which instructions are given to the patients. $\mathrm{X}$ axis denotes level of education and $\mathrm{Y}$ axis denotes number of patients. Most of the respondents from interns chose the option 'verbal' (Blue colour) and 'verbal and practical demo'(Yellow color).Chi square test shows a statistically significant difference in the responses among interns, specialists and practitioners [Pearson Chi square $p$ value $=0.002(p<0.05)]$.

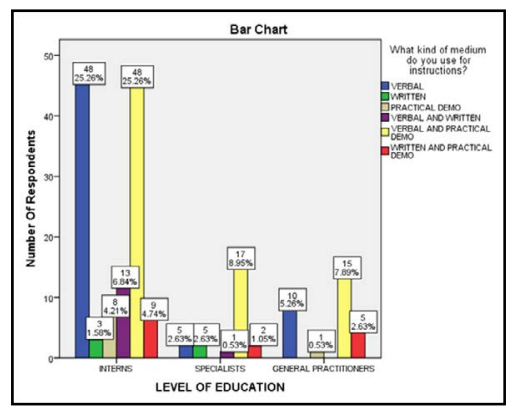

sionals should update themselves about new materials available in the market to create denture hygiene among patients such that the treatment will be successful in elderly patients. Oral hygiene and general health will be improved towards quality of life.

\section{Acknowledgement}

This research was done under the supervision of the Department of Research of Saveetha Dental College and Hospitals. We sincerely show gratitude to the corresponding guide who provided insights and expertise that greatly assisted the research. 
Figure 24. Bar chart depicting the association between place of practice and the explaining denture hygiene instructions to denture wearers is very time consuming. $X$ axis represents place of work and $Y$ axis represents number of respondents. Most of the respondents from Dental College chose the option 'Disagree' (Green colour) and 'Agree' (Blue color). Chi square test shows a statistically significant difference in the responses between Dental and the Private college [Pearson Chi square p value $=0.012 .(p<0.05)]$.

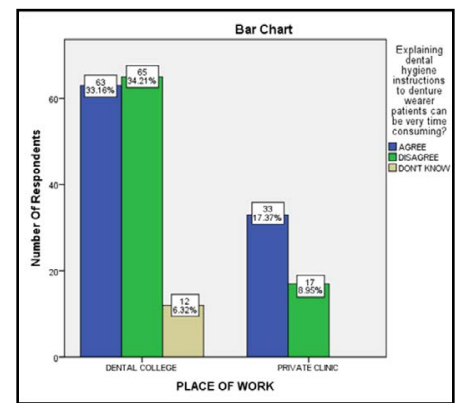

Figure 25. Bar chart depicting the association between gender and the recall program for complete denture patients is not important as denture teeth are artificial teeth.X axis shows gender and $\mathrm{Y}$ axis shows number of participants. Most of the respondents from females chose the option 'disagree' (green colour). Chi square test shows a statistically significant difference in the responses between male and female gender [Pearson Chi square $\mathrm{p}$ value $=0.000 .(\mathrm{p}<0.05)]$.

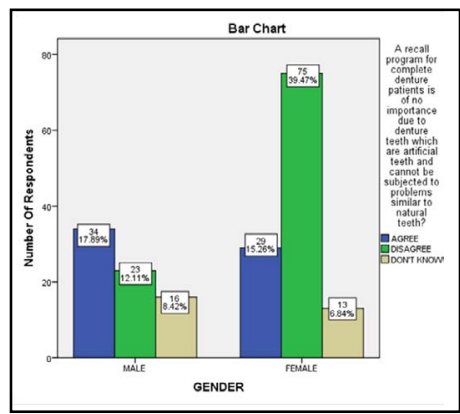

Figure 26. Bar chart depicting the association between gender and the method which the respondents recommend for denture cleansing to the patients. $\mathrm{X}$ axis denotes gender and $\mathrm{Y}$ axis denotes number of respondents Most of the respondents from female chose the option 'Brushing with water only' (Blue colour). Chi square test shows no statistically significant difference in the responses between male and female gender [Pearson Chi square $\mathrm{p}$ value $=0.694 .(\mathrm{p}>0.05)]$.

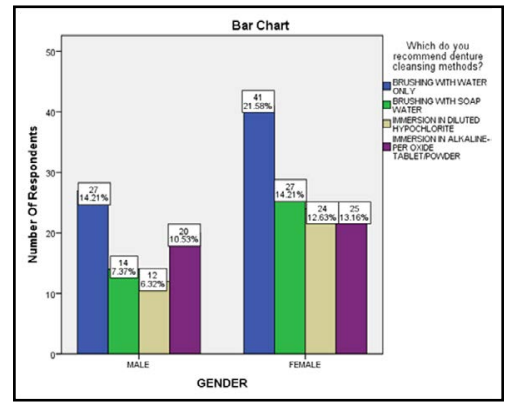

\section{References}

[1]. Baran I, Nalçacı R. Self-reported denture hygiene habits and oral tissue conditions of complete denture wearers. Archives of Gerontology and Geriatrics. 2009; 49(2): 237-41. Pubmed PMID: 18976822.

[2]. Petersen PE. Global policy for improvement of oral health in the 21 st century - implications to oral health research of World Health Assembly 2007, World Health Organization. Community Dentistry and Oral Epidemiology. 2009; 37(1): 1-8. Pubmed PMID: 19046331.

[3]. Petersen PE, Yamamoto T. Improving the oral health of older people: the approach of the WHO Global Oral Health Programme. Community Dent Oral Epidemiol. 2005 Apr; 33(2): 81-92. Pubmed PMID: 15725170.

[4]. Namrata M, Ganapathy D. Awareness about denture hygiene: A survey among patients wearing complete dentures and removable partial dentures. International Journal of Orofacial Biology. 2017 Jul 1; 1(2): 59.

[5]. Dikbas I, Koksal T, Calikkocaoglu S. Investigation of the cleanliness of dentures in a university hospital. Int J Prosthodont. 2006 May; 19(3): 294-8. Pubmed PMID: 16752629 .

[6]. Mylonas P, Afzal Z, Attrill DC. A clinical audit of denture cleanliness in general dental practice undertaken in the West Midlands. Br Dent J. 2014 Sep; 217(5): 231-4. PMID: 25213519.

[7]. Collis JJ, Stafford GD. A survey of denture hygiene in patients attending
Cardiff Dental Hospital. Eur J Prosthodont Restor Dent. 1994 Dec; 3(2): 67-71. PMID: 8605505.

[8]. Hoad-Reddick G, Grant AA, Griffiths CS. Investigation into the cleanliness of dentures in an elderly population. J Prosthet Dent. 1990 Jul; 64(1): 4852. PMID: 2384898.

[9]. Sheen SR, Harrison A. Assessment of plaque prevention on dentures using an experimental cleanser. J Prosthet Dent. 2000 Dec; 84(6): 594-601. PMID: 11125344

[10]. Paranhos Hde F, da Silva CH, Venezian GC, Macedo LD, de Souza RF. Distribution of biofilm on internal and external surfaces of upper complete dentures: the effect of hygiene instruction. Gerodontology. 2007 Sep; 24(3):162-8. PMID: 17696893.

[11]. Kulak-Ozkan Y, Kazazoglu E, Arikan A. Oral hygiene habits, denture cleanliness, presence of yeasts and stomatitis in elderly people. J Oral Rehabil. 2002 Mar; 29(3): 300-4. PMID: 11896849

[12]. Samaranayake LP, MacFarlane TW. A retrospective study of patients with recurrent chronic atrophic candidosis. Oral Surgery, Oral Medicine, Oral Pathology. 1981 Aug 1; 52(2): 150-3.

[13]. Sakki TK, Knuuttila ML, Läärä E, Anttila SS. The association of yeasts and denture stomatitis with behavioral and biologic factors. Oral Surg Oral Med Oral Pathol Oral Radiol Endod. 1997 Dec; 84(6): 624-9. PMID: 9431530.

[14]. Nagaral S, Desai RG, Kamble V, Patil AK. Isolation of Candida species from the oral cavity and fingertips of complete denture wearers. J Contemp Dent Pract. 2014 Nov 1; 15(6): 712-6. PMID: 25825095. 
[15]. Thiele MC, Carvalho Ade P, Gursky LC, Rosa RT, Samaranayake LP, Rosa EA. The role of candidal histolytic enzymes on denture-induced stomatitis in patients living in retirement homes. Gerodontology. 2008 Dec; 25(4): 229-36. PMID: 18312370.

[16]. Celić R, Knezović Zlatarić D, Baucić I. Evaluation of denture stomatitis in Croatian adult population. Coll Antropol. 2001 Jun; 25(1): 317-26. PMID: 11787557.

[17]. Khasawneh S, al-Wahadni A. Control of denture plaque and mucosal inflammation in denture wearers. J Ir Dent Assoc. 2002; 48(4): 132-8. PMID: 12622017.

[18]. Sadig W. The denture hygiene, denture stomatitis and role of dental hygienist. Int J Dent Hyg. 2010 Aug; 8(3): 227-31. PMID: 20624193.

[19]. Takamiya AS, Monteiro DR, Barão VA, Pero AC, Compagnoni MA, Barbosa DB. Complete denture hygiene and nocturnal wearing habits among patients attending the Prosthodontic Department in a Dental University in Brazil. Gerodontology. 2011 Jun; 28(2): 91-6. PMID: 20604810.

[20]. Rokade S, Pakhan AJ, Godbole SR, Sathe S. Evaluation of partially dentate patient's knowledge about denture hygiene-A survey. International J. of Healthcare and Biomedical Research. 2016 Jul; 4(04): 113-6.

[21]. Shay K. Denture hygiene: a review and update. J Contemp Dent Pract. 2000 Feb 15; 1(2): 28-41. PMID: 12167888

[22]. Paranhos HF, Silva-Lovato CH, Souza RF, Cruz PC, Freitas KM, Peracini A. Effects of mechanical and chemical methods on denture biofilm accumulation. J Oral Rehabil. 2007 Aug; 34(8): 606-12. PMID: 17650171.

[23]. Tarbet WJ, Axelrod S, Minkoff S, Fratarcangelo PA. Denture cleansing: a comparison of two methods. J Prosthet Dent. 1984 Mar; 51(3): 322-5. PMID: 6584599.

[24]. Milward P, Katechia D, Morgan MZ. Knowledge of removable partial denture wearers on denture hygiene. Br Dent J. 2013 Nov; 215(10): E20. PMID: 24231889.

[25]. AlEidan RF. Evaluation of Knowledge, Attitude, and Practices toward Complete Denture Hygiene among Dental Interns in Saudi Arabia. EC Dental Science. 2019; 18: 1181-8.

[26]. Suresan V, Mantri S, Deogade S, Sumathi K, Panday P, Galav A, Mishra K. Denture hygiene knowledge, attitudes, and practices toward patient education in denture care among dental practitioners of Jabalpur city, Madhya Pradesh, India. J Indian Prosthodont Soc. 2016 Jan-Mar; 16(1): 30-5. PMID: 27134425.

[27]. Samaranayake LP, Nair RG. Oral Candida infections--a review. Indian J Dent Res. 1995 Jul-Sep; 6(3): 69-82. PMID: 9495111.

[28]. Polyzois GL. Denture cleansing habits. A survey. Aust Dent J. 1983 Jun; 28(3):171-3. PMID: 6579930.

[29]. Schou L, Wight C, Cumming C. Oral hygiene habits, denture plaque, presence of yeasts and stomatitis in institutionalised elderly in Lothian, Scotland. Community Dent Oral Epidemiol. 1987 Apr; 15(2): 85-9. PMID: 3552396.

[30]. Jain AR, Nallaswamy D, Ariga P, Ganapathy DM. Determination of correlation of width of maxillary anterior teeth using extraoral and intraoral factors in Indian population: A systematic review. World J Dent. 2018 Jan; 9: 68-75.

[31]. Jyothi S, Robin PK, Ganapathy D. Periodontal health status of three different groups wearing temporary partial denture. Research Journal of Pharmacy and Technology. 2017; 10(12): 4339-42.

[32]. Selvan SR, Ganapathy D. Efficacy of fifth generation cephalosporins against methicillin-resistant Staphylococcus aureus-A review. Research Journal of Pharmacy and Technology. 2016; 9(10): 1815-8.

[33]. Ganapathy D, Sathyamoorthy A, Ranganathan H, Murthykumar K. Effect of Resin Bonded Luting Agents Influencing Marginal Discrepancy in All Ceramic Complete Veneer Crowns. J Clin Diagn Res. 2016 Dec; 10(12): ZC67-ZC70. PMID: 28209008.

[34]. Subasree S, Murthykumar K. Effect of Aloe Vera in Oral Health-A Review. Research Journal of Pharmacy and Technology. 2016; 9(5): 609-12.

[35]. Vijayalakshmi B, Ganapathy D. Medical management of cellulitis. Research Journal of Pharmacy and Technology. 2016; 9(11): 2067-70.

[36]. Ashok V, Nallaswamy D, Benazir Begum S, Nesappan T. Lip Bumper Prosthesis for an Acromegaly Patient: A Clinical Report. J Indian Prosthodont Soc. 2014 Dec; 14(Suppl 1):279-82. PMID: 26199531.

[37]. Venugopalan S, Ariga P, Aggarwal P, Viswanath A. Magnetically retained silicone facial prosthesis. Niger J Clin Pract. 2014 Mar-Apr; 17(2): 260-4. PMID: 24553044.

[38]. Basha FY, Ganapathy D, Venugopalan S. Oral Hygiene Status among Pregnant Women. Research Journal of Pharmacy and Technology. 2018; 11(7): 3099-102.

[39]. Pandurangan KK, Veeraiyan DN, Nesappan T. In vitro evaluation of fracture resistance and cyclic fatigue resistance of computer-aided design-on and hand-layered zirconia crowns following cementation on epoxy dies. J Indian Prosthodont Soc. 2020 Jan-Mar; 20(1): 90-96. PMID: 32089604.

[40]. Anjum AS, Ganapathy D, Kumar K. Knowledge of the awareness of dentists on the management of burn injuries on the face. Drug Invention Today. 2019 Sep 15; 11(9).

[41]. Ramya G, Pandurangan K, Ganapathy D. Correlation between anterior crowding and bruxism-related parafunctional habits. Drug Invention Today. 2019 Oct 15; 12(10).

[42]. Shree Y, Kumar K, Ganapathy D. [No title] [Internet]. [cited 2020 Jul 1]. Available from: https://www.researchgate.net/profile/Kiran_Pandurangan2/ publication/339873903_Awareness_of_basic_life_support_among_dental_students/links/5e69b30e458515c5de628420/Awareness-of-basic-lifesupport-among-dental-students.pdf

[43]. Inchara R, Ganapathy D, Kumar PK. Preference of antibiotics in pediatric dentistry. Drug Invent Today. 2019 Jun 15; 11: 1495-98.

[44]. [No title] [Internet]. [cited $2020 \mathrm{Jul} \mathrm{1].} \mathrm{Available} \mathrm{from:} \mathrm{https://www.}$ researchgate.net/profile/Kiran_Pandurangan2/publication/335523804_ Prevalence_of_toothpaste_swallowing_habit_in_children_between_ the_age_group_of_3_and_5_years/links/5d6a753da6fdcc547d6e8576/ Prevalence-of-toothpaste-swallowing-habit-in-children-between-the-agegroup-of-3-and-5-years.pdf

[45]. Srinivasan M, Gulabani M. A microbiological evaluation of the use of denture cleansers in combination with an oral rinse in complete denture patients. Indian J Dent Res. 2010 Jul-Sep; 21(3): 353-6. PMID: 20930343.

[46]. Gornitsky M, ParadisI I, Landaverde G, Malo AM, Velly AM. A clinical and microbiological evaluation of denture cleansers for geriatric patients in longterm care institutions. J Can Dent Assoc. 2002 Jan; 68(1): 39-45. PMID: 11844417.

[47]. Peracini A, Andrade IM, Paranhos Hde F, Silva CH, de Souza RF. Behaviors and hygiene habits of complete denture wearers. Braz Dent J. 2010;21(3): 247-52. PMID: 21203709. 